\title{
Understanding Differences between Equal Public Governance Models
}

\author{
Mirko Pečarič \\ University of Ljubljana, Faculty of Public Administration, Slovenia \\ mirko.pecaric@fu.uni-lj.si \\ https://orcid.org/0000-0002-0551-5682
}

Received: 29. 7. 2019

Accepted: 17. 12. 2019

\section{ABSTRACT}

Public administrations try to address changes in societies with various styles through various reforms based on different governance models, which are frequently transformed into domestic frames regardless of local specifics. The need for a tool with which the ideal types of governance models could be accommodated with national goals is, in times of increasing complexity, more and more relevant. As data as such are produced through numerous predispositions, the article proposes Ashby's variety to capture the latter, through which it is possible to get closer to a successful administration of goals. On the other hand, Douglas's grid and group model, Miles et al.'s organisational strategy, structure and process, and Hofstede's cultural dimensions are used for the identification of needs. Even though public bodies are aware of the impact that culture/ values has/have on models of public administration, countries base their decisions on it/them only indirectly. This article emphasises that certain values should be directly included in the governance models in accordance with their cultural backgrounds. The latter are always present in decisions' predispositions (from which decisions obtain their frames and weights), and a successful administrator should not disregard them.

Keywords: public governance models, cultural dimensions, public administration, reforms, side effects, univergency

JEL: K29

\section{Introduction}

Models are simplifications of the real world. Even when the same or similar styles of governance models, competences, legal rules or other arrangements in different legal systems are used, different results would still emerge. This can be seen e.g. in the EU member states' results using the same EU regulations. A gist is hence to know how a specific administrative tradition could be 
compatible not only with a specific governance model and the global, international or the EU's performance imperatives, but also with national (cultural) differences that serve as the formers' predispositions. Decisions' adverse effects could cause a pessimistic stance, but this could be improved if decisions' predispositions and/or their common denominators are known. Each governance model is also based on legal principles (e.g. Weberian on the rule of law, governance on transparency) that are not only the universal element of law, but also (in)directly express the basic cultural standpoints of society. These conditions predispose individual actions and describe the so-called Zimbardo's Situation: 'the bigger power for creating evil out of good [is] that of the System, the complex of powerful forces that create the Situation. A large body of evidence in social psychology supports the concept that situational power triumphs over individual power in given contexts' (Zimbardo, 2008, p. $x$ ). The core of culture 'is formed by values as broad tendencies to prefer certain states of affairs over others. They deal with pairings such as...following: evil versus good, dirty versus clean' (Hofstede et al., 2010, p. 9) etc. Values can serve as "normative patterns" through which norms are legitimised (Parsons, 1985). Works in this domain are focused on the relation between the values and electoral institutions (Katz, 1997), the values and economic (Ben-Ner and Putterman, 1998), on values that produce institutions and social norms (Argandona, 1991), on democratic values and institutions (Besley and Persson, 2019), values and accountability (Pečarič, 2018b) and legal principles as extrapolated reality (Pečarič, 2018a). Based on the mentioned connection between the governance models and legal principles, a research question is:

\section{RQ1: If countries want to minimise the side effects of their decisions/mod- els, should they consider their dependencies based on their (cultural) predispositions?}

As the science of public administration (PA) is built on general factors (the same as legal principles) that transcend national borders, this paper claims different practices or path dependencies of PAs can be reconciled with a new approach, here-called "univergent". This approach acknowledges universal platforms and differences at the same time (like the EU's motto "united in diversity" or the concept of universal service in regulated industries). The univergent approach is based on "universal diversity", i.e. the approach that recognises the known general elements of PA (e.g. centralisation, decentralisation, hierarchy, subsidiarity; in the legal side of PA it is present in the legal principles of administrative (aw), but also perceive differences that emerge by applying these general elements through (national/local) values. In the last decade of the $20^{\text {th }}$ century OECD claimed (in the instrumental manner) that basic PA values are shared between the EU member states and the EU candidate countries with the notion of "the European Administrative Space" (1999), while to the European Commission (in the semi non-instrumentalist manner) 'distinguishing principles as durable values is less important than ensuring the set of values governing public behaviour is clear and widely shared' $(2015, \mathrm{p} .17)$. The promotion of values by their enumeration and descriptions as the principles of good governance is not enough, because values emerge only within 
specific contexts, and in connection with specific actions. The latter in time transform external motions into intrinsic desirability as they become embedded in culture. Values from one country do not automatically work under different circumstances in another, and the same - based on different countries' scorings on various indexes - stands for the well-known Weberian or other governance models. European Commission admits 'there is very little rigorous research how values become integrated and ingrained in the culture of public administrations' (European Commission, 2015, p. 23). At first it should be known how values evolve, (re)act and change their content in different surroundings and how they can be implemented in different countries. How values or models capture the environmental dynamism, how they react in a predicted manner? The implementation of formally equal values/principles in a different environment produces different results from the "ideal type" governance models. This gap can be partially filled with institutional actions that change social practices, provided that a model's value is known. Based on the above-mentioned ideas (of univergency, predispositions, values, actions and principles) related with the Ashby's requisite variety (1957), Douglas's grid and group cultural model (2012), Miles et al.'s (2003) adaptation cycle model, and Hofstede's cultural dimensions (2010) the hypothesis is:

$\mathrm{H1}$ : The institutional environment depends on the fit between strategies, tools and implementation processes, when they derive their meanings and understandings from the cultural-value background.

$\mathrm{H} 1$ will be tested to answer on RQ1. The global competitiveness and human development indexes of countries will be used for this; both indexes are put into a four-quadrant cultural model. $\mathrm{H} 1$ is based on the predisposition that countries, which embrace a model that incorporates values as decisions' predispositions, can achieve a better fit between strategies and processes. To support this, a method will be presented that can help us understand how ideas are gradually transformed into values. By using the country-specific findings each country could better choose which decisions and means could be the most appropriate for its cultural context. The proposed method can also explain how national (cultural) differences - that should be considered - can be considered/changed to be better aligned with the dynamic environment. By these steps, countries can be armed with new perspectives and possibilities to reach the same goals by more effective paths. Decisions in PA depend on time, place, resources, their implementations and other factors, while values as decisions' predispositions depend on practices as path dependencies. The latter also causes for discrepancy between our inner values and the outer formal law. These differences will be shown in the second section, and will in turn be used in the third to address variety to be able to address the cultural conceptions of values in public reforms in the fourth section. In the fifth, differences between conceptions and countries will be used to show a platform (made by four basic dimensions of human character or culture) that will serve as a standpoint from which PAs' reforms can be explained de novo. The same platform as a model of universal value spectrum that embraces differences as 
its conditio sine qua non will also show implications for the PA's model in the sixth section, after which conclusion follows.

\section{Every model of governance has its specifics}

The example of New Public Management (NPM) is used here to show a discrepancy between the inner values and outer formal law. In the present time, when NPM's euphoria has subsided and increasingly resembles to other theories of PA that wanted to enhance the effectiveness and efficiency of PA. In Waldo's style decision-makers can ask "Efficiency for what" (1948)? If they want relevant answers, they should ask who, what, when, how and with what something should be done. Answers would probably be to some point different for each PA. For Ongaro 'the basic note [of public reforms] seems to be one of continuity: the public administration of the five countries under examination [Portugal, Greece, Spain, France and Italy] still displays many of the basic characteristics that could be found 30 or 40, or many more, years ago' (2010, p. 263). According to Pollit and Bouckaert (2011) from the late 1990s to 2010 there is '[n]o dominant model [of public management, but rather] several key concepts, including governance, networks, partnerships, "joining up", transparency, and trust' (2011, p. 11). There are many specifics in every country, and any kind of "good" ideas should be handled with care: 'far from being new-minded in the 1980s, most of the basic ideas about how to manage in government have a history... [so] we need to be wary of taken-for-granted assumptions about who is to count as a manager of public services, what management means, what "best practice" amounts to and who or what to blame when things go wrong' (Hood, 1998, p. 22). There is neither time nor space to further enumerate all authors that have elaborated the positive and negative effects of the PA reforms (Crozier, 1964; Merton, 1968; Simon, 1997), but they would probably agree that each administration has a positive potential vis-à-vis positive effects, which can become also negative.

Decision-makers should be aware on different contexts in which decisions/ models are taken/used; solutions depend on numerous elements that include also the unknown, uncertain or probable, which might undermine desired results. Many times, partial successes are present with side effects produced. The principle of care cannot per se provide appropriate grounds for making decisions without taking differences into account. Despite numerous claims about inter- and multi-disciplinarity PAs need a wider perspective from which evaluation, balance or better explanation of intended actions can be understood. PAs have along the different characteristics and specifics also differences present in the apparently equal elements: what can be good somewhere can be bad in other place (one man's poison is another man's cure ${ }^{1}$ ). Nature is more complex than people; there is always more variety in the world than can ever be built into any kind of governance model. Yet we ought to be aware of what we can still do - unintended consequences or side effects

1 Variety or relativity is known for a long time: the Roman poet Lucretius coined the expression in the first century BC, "quod ali cibus est aliis fuat acre venenum" (what is food for one man may be bitter poison to other). 
emerge due to non-understanding of variety, and to build a more relevant model of PA or to make an effective decision the understanding and administration of variety is required.

\section{Variety}

Ashby proposed variety as the measure for complexity in the 1950s. For him '[a]n essential feature of the good regulator is that it blocks the flow of variety from disturbances to essential variables' (Ashby, 1957, p. 201). If variety in outcomes is to be reduced to some assigned number, than a regulator's variety of tools vis-à-vis environment 'must be increased...to at least the appropriate minimum' (Ashby, 1957, p. 206). Only Variety can force down Variety and vice versa: only variety can destroy variety. Ashby's variety balances the system from a control standpoint between the regulator and the outer environment. A homeostatic loop of the regulator's amplifiers (from the regulator to the system) and filters (from the system to the regulator) is inserted to deal only with an interested part of the environment, because the latter is too complex to deal with it as a whole. Complex adaptive systems are the 'systems that involve many components that adapt or learn as they interact' (Holland, 2006, p. 1) have a characteristic element known as emergence: '[a]n emergent property is a global behaviour or structure which appears through interactions of a collection of elements, with no global controller responsible for the behaviour or organisation of these elements. The idea of emergence is not reducible to the properties of the elements' (Feltz et al., 2006, p. 241). With its regulatory and learning element it is no wonder why variety and complexity has attracted attention also of scholars, who tried to transfer complex systems theory to organisations and PA. Efforts include works of Senge (2010), Stacey (1992), Wheatley (Wheatley, 2006), Goldstein (1994), and others (Bovaird, 2008; Haynes, 2008; Klijn, 2008; Teisman and Klijn, 2008), but Rhodes and her colleagues (Eppel and Rhodes, 2018a, 2018b; Koliba et al., 2016; Rhodes, 2008; Rhodes et al., 2010; Rhodes and MacKechnie, 2003; Rhodes and Murray, 2007) conclude 'there has been little attention paid to how this research [on complexity theory] has translated into practice or into the teaching of public administration' (Eppel and Rhodes, 2018a, p. 1).

Complexity represents things with many parts that interact with each other in multiple relations, while variety is the measure for defining the number of those possible relations. Performance criteria - that are so emphasised in quality management - can be set only after we have identified goals and available tools as the amplifiers and filters (the non-identification of these tools could be fatal for many PAs). The larger the variety of actions controllers can have, the larger the variety of perturbations that must be compensated. There should be as many elements on the one side as there are on the other side, if one wants to establish variety in their relations (requisite variety). ${ }^{2}$ Requisite variety is a tool that can give decision-makers the appropriate mo-

2 If it is almost self-evident that two sports teams should have a same number of players, this self-evidency is somehow lost in more important things... 
dus operandi with which they can are closer to their goals; in order to deal effectively with diverse problems, there must be multiple responses that should be as nuanced as the problems at hand. This approach is sine qua non for managing variety, but it cannot give us an answer to why one alternative was chosen instead of another. Which decisions are chosen and implemented can depend on causes hidden in our cultural values as predispositions. As will be demonstrated in the next chapters, values are not only present in our decisions, but form a very influential part, although we are mostly unaware of this - pre-decisional - point.

\section{Cultural conceptions of values in public reforms}

For Durkheim as the author of the concept of (mechanical and organic) solidarity, social solidarity is a moral phenomenon, which is not amenable to exact observation and measurement, so 'we must substitute this internal datum with a visible one, with the law' (1984, p. 24). Despite of differences between solidarity and law, they can be put into the same frame within one culture as their denominator. And Mary Douglas did precisely this: "[a]rguing from different premises, we can never improve our understanding unless we examine and reformulate our assumptions' (1986, p. 8), so any kind of decision can exist only when individuals have the common categories of thought. Both Durkheim and Douglas point to public institutions that primarily formulate assumptions for the public, and these assumptions are built into decisions. As public institutions are authority figures their decisions will be respected up to a certain point, but their decisions could be more effective, if they targeted our common assumptions. 'Ideas and values only become strongly entrenched when they are embedded in institutions' (Douglas, 2012), while the latter are embedded in a nation's culture. To cultural theory a boundary line between the legal and the non-legal is not self-evident, because it is socially constructed; classification is thus a creation of culture: '[t]he culturally learned intuitions guide our judgment for any of our fields of competence, [and] teach us enough probabilistic principles, but they are heavily culture bound' (Douglas, 1994, p. 57). Cultural theory can help us describe the complexity of modernisation because it shares a common denominator. The inherited ideas, beliefs, and values bind society together, and are also present in the public law; the latter more or less binds us to one another through the public interest and solidarity. The public opinion analysis or opinion should not be used only for the enhanced consultation and dialogue with citizens in search for higher legitimacy, but to gain insight into the people's motivations, feelings and reactions with regard to a particular topic. We will try to show how culture reflects our decisions and/or also the (un) successfulness of public reforms. 


\subsection{The grid and group cultural model}

One of the well-known typologies for the distribution of values within a population is Douglas's grid and group analysis (Douglas, 1982, 2003, 2012); ${ }^{3}$ it shows connections between the different kinds of social organisation and values that uphold them. Her model of the distribution of values gives - under the grid and group as the basic dimensions of sociality - a fourfold typology of solidarities or four ideal types of cultural bias: individualism, hierarchy, fatalism and egalitarianism:

Diagram 1: Some synonyms for the four quadrants of grid and group

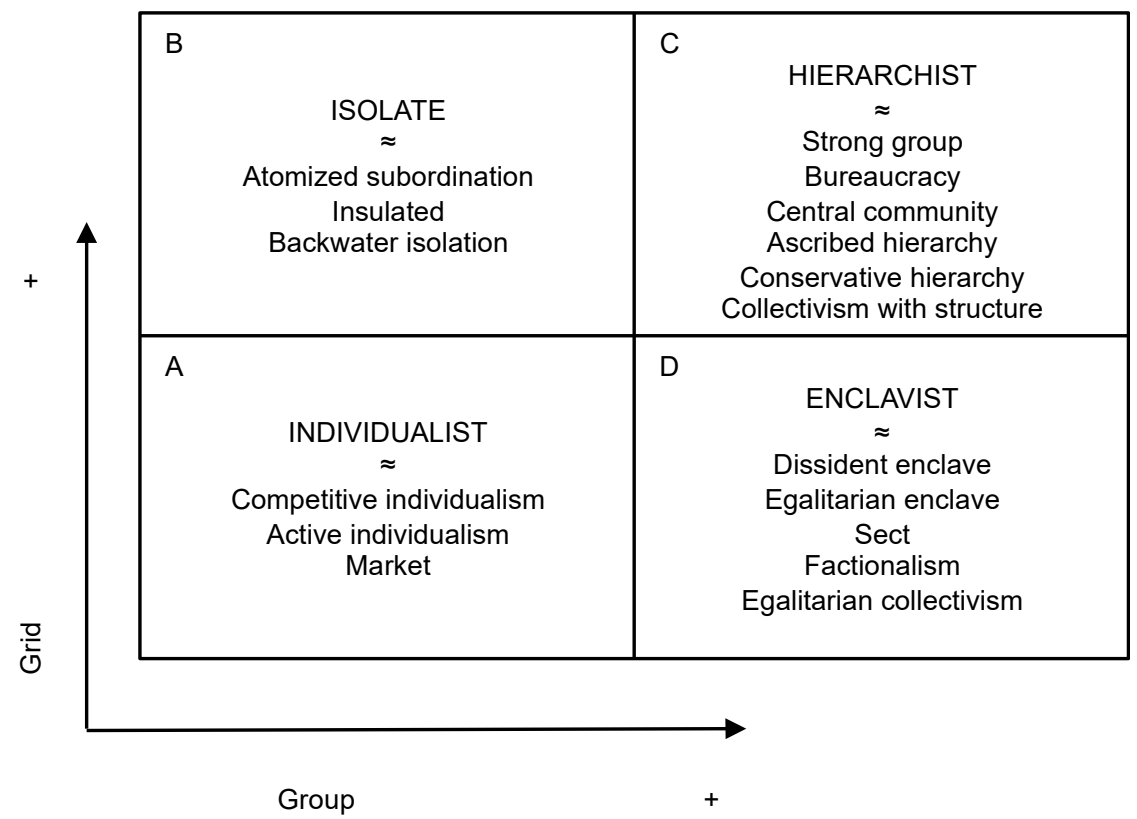

Source: Fardon, 1999, p. 224.

Douglas's GGCT model was applied by Hood in the field of public management: 'a cultural-theory approach has much to offer to the art of the state as a framing approach for thinking creatively about available forms of organization and in exploring the variety of what-to-do ideas that will always surround public services and government' (1998, p. 241). To him '[t]here is no universal agreement on what counts as "problem" and what as "solution", or when the point is reached where the "solution" becomes worse than the "problem"' (1998, pp. 24-25). For the individualist good administration happens within the market and is driven by competition, for the hierarchist it is present in expertise and authority within government, for the egalitarian it can be achieved by consensus, while the fatalist (in isolation) does not even

3 The group dimension taps the extent to which 'the individual's life is absorbed in and sustained by group membership', while the grid dimension is characterised by 'an explicit set of institutionalised classifications that keeps individuals apart and regulates their interactions' (Douglas, 1982, pp. 202-203). 
care for it and does not think about many unpredictable/side effects of planning, so s/he just goes with the flow. For Douglas, all cultures can be assessed and classified according to these ways of life, which constitute an exhaustive list of viable cultural possibilities. This however cannot yet provide sufficient grounds for understanding them; countries should know what values prevail within their borders to effectively apply reforms, and a warning should be made before transferring legal institutes from other countries that do not have the same values. Regulation places constraints on a specific nation's cultural platform, by providing (dis)incentives for human behaviour, markets and companies (Ashby's requisite variety is hence a method of operation to amplify or to filter, not a goal per se). We have to select the most appropriate regulative and economic tools (as amplifiers and filters) from those that are legally and materially available. Regulatory approaches require changes in behaviour by introducing negative/positive effects for those who do or do not comply with regulatory provisions. Only then can requisite variety achieve its goal. Douglas's GGCT model can be used for a better interpretation of a particular regulatory tool and its placement into a specific field within the square according to people's preferences. An analysis of people's preferences would give better opportunities to choose the most appropriate policies and their corresponding tools. An online voting platform for people to voice their opinions and choices by filling in questionnaires or surveys on political views or similar issues important to them could provide a better means of selecting the most appropriate regulatory tool. This could be implemented by IT and as a matter of fact - it has been already done. We refer to Hofstede's cultural dimensions that will be presented in the subchapter 4.3 .

\subsection{Strategy, structure and process}

Before we turn to Hofstede's dimensions we must mention another model that is similar to Douglas's GGCT model, namely the adaptive cycle model of Miles et al. (1978). Within this model there are three "problems" of organisational adaptation: the entrepreneurial problem (goal - strategy), the engineering problem (system - technology) and the administrative problem (structure - process). Performance depends on the adoption of strategies, systems and processes that are aligned with an organisation's environment. Organisations must employ strategies for solving problems according to essentially three strategic types of organisation: Defenders, Analysers and Prospectors, ${ }^{4}$ while

4 1. Defenders are organizations which have narrow product-market domains. Top managers in this type of organization are highly expert in their organization's limited area of operation but do not tend to search outside their domain for new opportunities. These organizations seldom need to make major adjustments in their technology, structure, or methods of operation. Instead, they devote primary attention to improving the efficiency of their existing operations. 2. Prospectors are organizations which almost continually search for market opportunities, and they regularly experiment with potential responses to emerging environmental trends. However, because of their strong concern for product and market innovation, these organizations are usually not completely efficient. 3. Analysers are organizations which operate in two types of product-market domains, one relatively stable, the other changing. In their stable areas, these organizations operate routinely and efficiently through use of formalized structures and processes. In their more turbulent areas, top managers watch their competitors closely for new ideas, and then they rapidly adopt those which appear to be the most promising. 4. Reactors are organizations in which top managers frequently perceive change 
the fourth, Reactor, is residual and occurs when a business lacks insight, or if it fails to take advantage of alignment opportunities afforded by the adaptive cycle. Andrews et al. (2012), based on the work of Miles and Snow (2003), focused on the impact of strategic management on the effectiveness of public services. They confirmed their hypotheses on structure and strategy content:

high performance appears to be more likely for public organizations that match their decision-making structure with their strategic stance. Defending organizations with a high degree of hierarchical authority and low staff involvement in decision-making, in particular, perform better, but prospecting organizations with high decision participation are also likely to do well. By contrast, hierarchy of authority and participation in decision-making make no difference to the performance of reacting organizations (Andrews et al., 2012, pp. 124-125).

They have statistically confirmed that the degree of both hierarchy of authority and participation in decision-making are unrelated to how well services perform, but on the other hand, strategies work better if they are aligned with the organisational structure: rational planning with hierarchy and centralisation (while centralisation is unrelated to performance with an absence of strategy), and logical incrementalism with decentralised responsibility. 'Reactors perform better only when they are subject to regulation that complements their existing strategic orientation' (2012, p. 145). 'Prospecting will improve performance if carried out in combination with a high level of decision participation... [while] organizations that adopt a defending strategy enhance their performance if they centralize authority and reduce decision participation' (2012, p. 122). Public managers should not seek the best strategy but ought to identify and accommodate the many contingencies that shape the success of different strategies: 'what counts is the combination of strategy with other influences on organizational outcomes' (2012, p. 150). If we want the right fit between the desired goals we should be aware of ways that form them. Miles and Snow are one step ahead of Douglas because they emphasise the right fit between strategy, system and process, and not just the strategic typologies. The latter can be aligned with Douglas's GGCT model in the

and uncertainty occurring in their organizational environments but are unable to respond effectively. Because this type of organization lacks a consistent strategy-structure relationship, it seldom makes adjustment of any sort until forced to do so by environmental pressures (R. Miles \& Snow, 2003, p. 29)endlessly. But a few do stick, and this book is such a one. Organizational Strategy, Structure, and Process broke fresh ground in the understanding of strategy at a time when thinking about strategy was still in its early days, and it has not been displaced since.|"-David J. Hickson, Emeritus Professor of International Management \& Organization, University of Bradford School of ManagementOriginally published in 1978, Organizational Strategy, Structure, and Process became an instant classic, as it bridged the formerly separate fields of strategic management and organizational behavior. In this Stanford Business Classics reissue, noted strategy scholar Donald Hambrick provides a new introduction that describes the book's contribution to the field of organization studies. Miles and Snow also contribute new introductory material to update the book's central concepts and themes.Organizational Strategy, Structure, and Process focuses on how organizations adapt to their environments. The book introduced a theoretical framework composed of a dynamic adaptive cycle and an empirically based strategy typology showing four different types of adaptation. This framework helped to define subsequent research by other scholars on important topics such as configurational analysis, organizational fit, strategic human resource management, and multifirm network organizations." 
following way: Hierarchist - Defender; Individualist - Prospector; Enclavist Analyser; Isolate - Reactor. This typology and Douglas's GGCT model will be now used in Hofstede's cultural dimensions.

\subsection{Dimensions}

Geert Hofstede has examined variations in values and organisational norms over three decades across fifty countries. A cultural perspective has quite a lot to do with public management reform because 'Hofstede's measures... reflect the broad cultural climates in which management reforms will have to be announced, interpreted, promoted, and resisted in each particular country' (Pollitt and Bouckaert, 2011, p. 64). In the style of cultural relativism, Hofstede et al. claim that ' $[w]$ e cannot change the way people in a country think, feel, and act by simply importing foreign institutions... Each country has to struggle through its own type of reforms, adapted to the software of its people's minds' (2010, p. 25). According to them there are six dimensions of culture that can be measured in relation to other cultures, but here we shall use only the $1^{\text {st }}, 2^{\text {nd }}$ and $4^{\text {th }}$ dimension (because the $3^{\text {rd }}, 5^{\text {th }}$, and $6^{\text {th }}$ one [Femininity versus Masculinity, Long-term versus Short-term Orientation and Indulgence versus Restraint] cannot be connected with Douglas's GGCT model and Miles and Snow's strategic typologies - these will all later be put in the model of ranking values in cultural dimensions):

Power Distance is defined as "the extent to which the less powerful members of institutions and organizations within a country expect and accept that power is distributed unequally" (ibid, p. 61). Collectivism versus Individualism: "individualism pertains to societies in which the ties between individuals are loose: everyone is expected to look after him or herself and his or her immediate family. Collectivism as its opposite pertains to societies in which people from birth onward are integrated into strong, cohesive in-groups, which throughout people's lifetime continue to protect them in exchange for unquestioning loyalty" (ibid, p. 92). Uncertainty Avoidance: "the extent to which the members of a culture feel threatened by ambiguous or unknown situations" (2010, p. 191).

If these dimensions and their specifics are applied to states' actions, differences between states can be seen or easily understood. The following sections of this paper attempt to do this: Hofstede's cultural dimensions can be at first compared with Douglas's GGC model (the latter is similar to Hofstede's collectivism versus power distance - first two dimensions). It is possible to compare them because they contain similar elements: power distance corresponds to grid, while individualism versus collectivism corresponds to group. Many countries that score high on the power distance index (PDI; the horizontal axis) score low on the individualism index (IDV; the vertical axis), and vice versa. They are either hierarchical or individualistic. Countries with low PDI and IDV are enclavist, and those with high PDI and IDV are isolative. While the first two fit very well into Hofstede's classification, the enclavist and isolative do not. It should be stressed that Douglas's model is an ideal type. It is a useful methodological device to begin the comparison of biases within related cultures 
with; however, a social reality is more complex. Her description of the isolate and egalitarian positions can hold if we are within ${ }^{5}$ a nation's culture, but if we compare cultures, then these positions exchange places: isolate becomes egalitarian and vice versa. Countries with a high grid value and a low group value are more consensus-oriented, egalitarian, there rankings and ordering are the usual ways of controlling the social impact, and they have (modest) citizen participation, problems of leadership, authority and decision making, whereas countries with a low grid value and a high group value (from their point of view) might be more influenced by randomness, isolation and dependence on other countries. This is more clearly presented in the following section.

\section{Between conceptions and countries}

The legal and administrative framework within which individuals, companies, and governments interact to achieve their goals determines an institutional environment, which is co-determined also by socio(cultural)-economic context. While the latter is mainly influenced by technology, place and time, the institutional environment depends on the fit between strategies, tools and procedures of implementation processes. We shall verify this by analysing the global competitiveness (because we are interested in PAs, we shall look at the elements of the quality of institutions and the quality of life) and human development indexes. Both indexes for specific countries are put into Hofstede's PDI v. IDV model (Figure 1). The numbers added into his model are the rankings of quality of institutions from The Global Competitiveness Report 2012-2013 (Schwab, 2012), and the numbers in the brackets are the Human Development Index 2011 rankings (2011):

5 The extreme top on the left side has strong grid controls, without any group membership to sustain individuals. Anyone who arrives here is a cultural isolate... as far as public policy is concerned. Isolates attract no attention; no one asks for their opinion or takes them seriously in argument. Hence their reputation of apathy (Douglas, 2012). 
Figure 1: Power Distance versus Individualism ${ }^{6}$

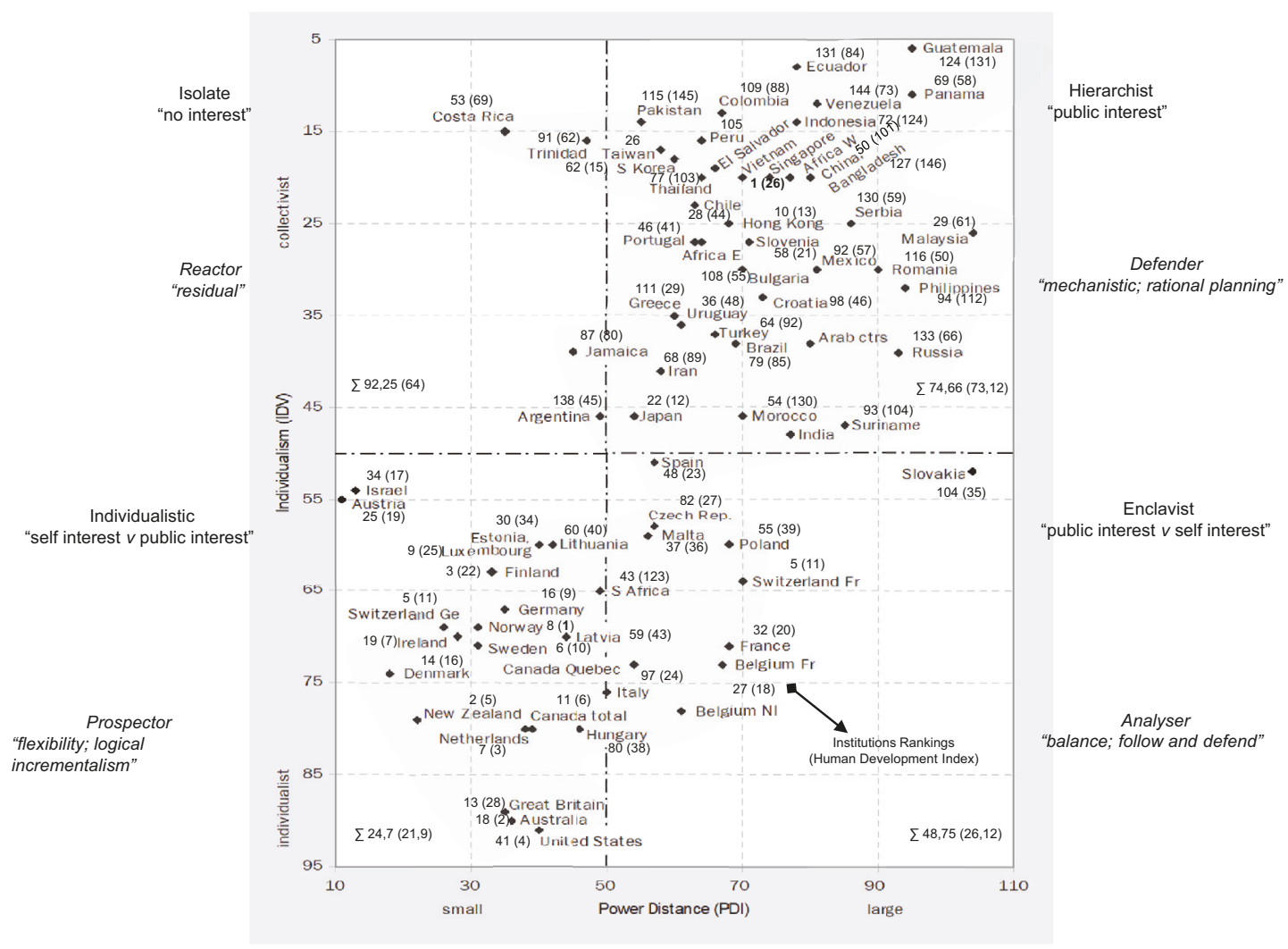

As can be seen in the Figure 1 the highest-ranking institutions and the highest quality of life can be found in the Prospector (Individualist) countries (e.g. Norway, New Zealand, the Netherlands), but also in the Defender (Hierarchist) countries (e.g. Singapore, Japan). While this confirms the analysis of Andrews et al. that neither centralised nor decentralised decision-making has an independent effect on the public service performance, the average number of countries in each quadrant confirms even more Miles and Snow's (2003) argument that an organisation's overall strategy must fit to its environment, organisation structures and management processes, whereas the entire organisation must continually adapt in order to maintain its fit over time. The top countries can be found in the lower quadrants and in the right upper quadrant, but the average numbers show that 1 ) the area of Prospector $(\Sigma 24,7[21,9])$ is the most favourable place for institutions and in terms of the quality of life; 2$)$ the area of Analyser $\left(\sum 48,75[26,12]\right)$ is in the middle of those countries where the quality of institutions drops faster than the quality of

6 The basic scheme is taken from Hofstede et al. (2010, p. 103). The following has been added to the original scheme: the quality of institutions and human development indices, a grey area indicating the dominant positions of countries between the PDI and IDV, and descriptions next to individual quadrants pointing out the prevailing ideas according to Douglas's GGCT model and Miles and Snow's model of adaptive cycle. 
life; and 3$)$ in the area of Defender $(\Sigma 74,66[73,12])$ the quality of institutions is lower than that of Analyser and higher than that of Reactor ( $\Sigma 92,25$ [64]), but the quality of life is the lowest. The distribution of countries in quadrants presented by the given averages $(\Sigma)$ shows that it is erroneous for governments to use the same approach and tools for different goals or even for the same goals in different times or places. The Defender (Hierarchist) countries can be as good as the Analyser (Enclavist) or Prospector (Individualist) ones, while all must take care of the right fit between goals, tools and processes. In large power distance countries, hierarchy causes a considerable dependence of subordinates on the rulers and rules or vice versa, on rational planning, centralisation and information channels. Defender should use Defender's tools and processes, Analyser and Prospector their own, while Reactor usually uses those of Defender. Collectivist countries should be careful when using individualistic methods for economic incentives, while individualistic countries could use collective methods mainly for the rule of law and the basic social welfare.

Figure 1 can also highlight a set of ideal types for managing performance. People always want to decrease uncertainty (a source of anxiety). As the laws and rules are among other methods (religion, culture, technology) most "convenient" for diminishing uncertainty, uncertainty avoidance can be presented to show differences between countries (Figure 2), foremost because of its similarity with the law, i.e. with legal certainty and legal expectations: 
Figure 2: Power Distance versus Uncertainty Avoidance ${ }^{7}$

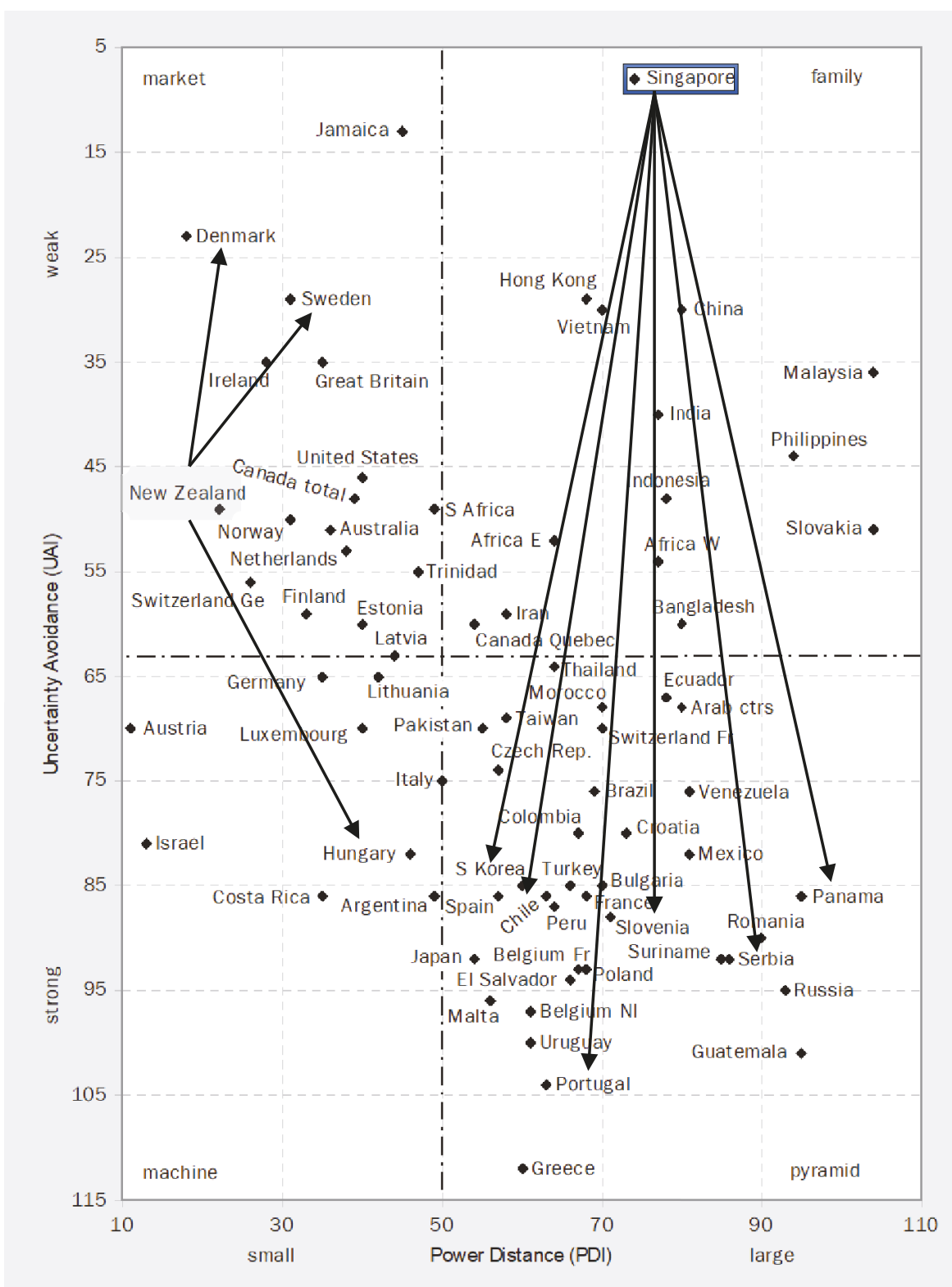

In the Figure 2, Singapore and New Zealand are the starting points, being the countries of the first and of the second rank in terms of the quality of institutions. The arrows point from these two countries to the countries that are in their neighbourhoods, while here are placed more apart due to the un-

7 The basic scheme is taken from Hofstede et al. (2010, p. 303). The arrows added to the original figure show how some countries that are close to each other in the PDI - IDV model are here separated. 
certainty avoidance dimension. The countries that are within the quadrant of individualistic countries (with a low PDI and a high IDV) in the PDI - IDV model retained a more similar position than the countries with a high PDI and a low IDV. Due to the added uncertainty avoidance dimension, the countries with a high PDI and a high IDV are now more similar to some countries with a low IDV (Portugal, Slovenia, Serbia, S Korea and Chile ${ }^{8}$ with France and Belgium). Although the last two states place high value on individualism, it seems that it is not as powerful as in the countries with the same degree of individualism but with a smaller PDI (otherwise the uncertainty avoidance value would be similar as for the first cited countries). According to the global competitiveness index, the inefficient government bureaucracy is among the most problematic factors for doing business (Schwab, 2012). The Power Distance versus Individualism and Power Distance versus Uncertainty Avoidance figures can give some explanation why the NPM's "euphoria" cannot bring good results for the NPM in the areas of Reactor, Defender or Analyser (from worse to less bad): countries in these areas have other backgrounds, and use different models for institutions and rules. Some of the NPM's ideas (e.g. "let the middle managers manage" and/or "slim down central civil service") are not as easily achieved in the countries with a high PDI and a high(er) IDV as they can be in those with a low PDI and a low(er) IDV.

\section{Implications for the models of public administration}

What can be recommended for PAs according to the applied method? Well, countries in the Prospector area (Individualist), with a high IDV and a low PDI (see the lower left quadrant in Figure 1), are on average the best for maintaining competitiveness and the quality of life - but only on average. Top countries in terms of these criteria are also found in the Analyser (Enclavist) and Defender (Hierarchist) areas, although they represent a minority among the countries of the same type. Creating a strategy with appropriate tools and processes is vital for the overall success. Introducing the NPM in hierarchical countries might cause side effects of the larger bureaucracy, more public servants, wastefulness, re-regulation, higher corruption ${ }^{9}$ etc., because such countries are not accustomed to the decentralised methods of organisation and individualistic mentality; contrary, individualistic countries - to which the model of NPM is the most appropriate - should be cautious about introducing hierarchical elements because these diminish democracy and freedom, as well as enhance control and obedience. Those are all elements of centralised, Weberian organisations, which from the collectivist point of view are essential for good administration. People living in hierarchical countries do not view

8 These countries - if they want to reduce uncertainty - should model themselves more after the main features of public administration Singapore-style and transfer them according to their contexts. For the main features of the public administration in Singapore see (Quah, 2010). The above-mentioned countries should also reduce collectivist elements, which would bring them closer to France or Belgium.

9 From 2001 to 2011 the Corruption Perception Index mostly got worse for hierarchical countries: Slovenia (34-37), Croatia (47-62), Russia (79-133), Romania (69-66), Hong Kong (1414), Brazil (46-69), Turkey (54-54), Greece (42-94), Thailand (61-88), Taiwan (27-37), Malaysia (36-54). Available at: http://www.transparency.org (accessed 20 December 2018). 
their freedom as the people in the individualistic ones; they have a different perspective, so it is not useful to talk about less freedom from the individualistic point of view in hierarchical countries, just as it is useless to talk about the "selfish" individualistic mentality from the hierarchical point of view.

Exporting ideas or models of governance to other countries without regard to their respective contexts and values into which new ideas are transferred can have a limited success (although the transfer is well-intentioned); failures are then described as inefficiency, illegality, corruption etc. Every country has its own causes for a prevalence of specific values (they have proved successful during a country's history; they have stored information that is constantly transmitted into values). Values can be changed only gradually, and by small steps. Culture is influenced by our experiences not by our genes. A human power to move and change physical things is, or can be, used for the efficient control over our psychological elements, which we can influence indirectly through our activity:

Because we always have control over our component of behaviour, there are also simultaneously - if we significantly change our behaviour - changed components of thinking and feeling and our physiology. The more we actively engage in the active behaviour...the more we will also revise our thoughts, feelings, and listen to what our body tells us. If this gives us greater control, there will also be better feelings, more pleasant thoughts, and physical comfort (Glasser, 1994, p. 51).

Activities that cause failure or success are usually formed in a sequence; each level represents its distinct tendency, but together they form an interactive whole in which higher levels provide the context for the lower ones. The same stands for institutions and their models of governance. We should thus be attentive to new circumstances, to the "new rules of the game". The cumulative effects of these stages ultimately manifest themselves in a shift of paradigm, from "it has always been done this way" to "we are going to challenge our assumptions as often as we can". Unpredictability can be undermined by prediction and preparation. Multi-minded purposeful organisations are the basic requirement for all countries (i.e. with a high or a low PDI or IDV) to enable the amplifiers and filters (managing variety) to be formed at the right time and place. There is a constant need for better information in public administration, but apart from information a commitment to evaluate it - and to change our practices if this is necessary for better results - is also welcome. An answer to what is needed, urgent or what is better can be found only in the relative (higher or lower) importance of our goals that emanate from our values.

\section{Conclusion}

The science of PA can build its elements on predispositions that are different from the present ones. A country's cultural and socio-economic context can give more relevant predispositions (cultural dimensions) upon which deci- 
sions and tools for their implementation should be made and/or operate in a certain country. Decision-makers should be aware of different cultural, social, economic and other countries' backgrounds, because they cause differences among countries. These differences as values should fit to strategies, tools and implementation processes: the better fit means the higher rank. $\mathrm{H} 1$ is thus confirmed and with this also the answer on RQ1: countries should consider relations between decisions and their cultural backgrounds. Good governance can be established in a frame of different values without affecting the idea of good governance itself. It is backgrounds that decide what will work and what will not - not in an absolute sense, but they can undermine otherwise well-intentioned plans. Cultural predispositions as the real purpose in action can be slowly changed by longevity, determination and modelling behaviour if appropriate strategies, tools and processes are used. The institutional environment depends on the fit between strategies, tools and implementation processes, while they all derive their meanings and understandings from the cultural-value background. Countries should consider dependencies between decisions and their (cultural) predispositions; the ranking of values in cultural dimensions can give us a better platform with which decisions can be customized to a country's specifics, while each country is on its own decisional path and actions. A general, nomothetic recipe cannot bring the same results in different countries. This paper emphasised the countries' inevitable differences and specifics that form their specific varieties. The latter can be tamed only with opposite varieties within the mix of organisational strategy, structure and process that corresponds to specific cultural dimensions. Reforms can be successful, not only if they include cultural dimensions, but primarily if they serve as the starting point of reforms. From these standpoints the value of governance models can be established for a specific country.

The author gratefully acknowledge the project The Development of a Holistic Governance Model for an Efficient and Effective Slovenian Public Administration (J5-8238) was financially supported by the Slovenian Research Agency. 


\section{References}

Andrews, R. et al. (2012). Strategic Management and Public Service Performance. Palgrave Macmillan.

Argandona, A. (1991). Values, Institutions and Ethics, Workin paper no. 218. IESE Business School, University of Navarra. At<https://media.iese.edu/research/ pdfs/DI-0215-E.pdf>, accessed 20 May 2019.

Ashby, W. R. (1957). An Introduction to Cybernetics. Chapman and Hall.

Ben-Ner, A. and Putterman, L. (1998). Values, Institutions, and Economics. The Good Society, 8(2), pp. 14-16.

Besley, T. and Persson, T. (2019). Democratic Values and Institutions. American Economic Review: Insights, 1(1), pp. 59-76. <doi.org/10.1257/aeri.20180248>

Bovaird, T. (2008). Emergent Strategic Management and Planning Mechanisms in Complex Adaptive Systems. Public Management Review, 10(3), pp. 319-340. <https://doi.org/10.1080/14719030802002741>

Crozier, M. (1964). Bureaucratic Phenomenon (1 ${ }^{\text {st }}$ edition). University of Chicago Press.

Douglas, M. (1982). Essays in the Sociology of Perception. Routledge Kegan and Paul.

Douglas, M. (1986). How Institutions Think. Syracuse University Press.

Douglas, M. (1994). Risk and Blame: Essays in Cultural Theory. Routledge.

Douglas, M. (2003). Natural Symbols: Explorations in Cosmology (3rd edition). Routledge.

Douglas, M. (2012). A History of Grid and Group Cultural Theory. At <http:// projects.chass.utoronto.ca/semiotics/cyber/douglas1.pdf>, accessed 23 May 2019.

Eppel, E. A. and Rhodes, M. L. (2018a). Public Administration \& Complexity-How to teach things we cannot predict? Complexity, Governance and Networks, 4(1), pp. 1-9.

Eppel, E. A. and Rhodes, M. L. (2018b). Complexity theory and public management: A 'becoming' field. Public Management Review, 20(7), pp. 949-959. https://doi.org/10.1080/14719037.2017.1364414

European Commission. (2015). Quality of Public Administration-A Toolbox for Practitioners. European Union. At <https://ec.europa.eu/digital-singlemarket/en/news/quality-public-administration-toolbox-practitioners>, accessed 5 March 2019.

Fardon, R. (1999). Mary Douglas: An Intellectual Biography. Routledge.

Feltz, B. et al. (2006). Self-organization and Emergence in Life Sciences. Springer Science and Business Media.

Glasser, W. (1994). Kontrolna teorija. Taxus.

Goldstein, J. (1994). The Unshackled Organization: Facing the Challenge of Unpredictability Through Spontaneous Reorganization. CRC Press.

Haynes, P. (2008). Complexity Theory and Evaluation in Public Management. Public Management Review, 10(3), pp. 401-419. https://doi.

org/10.1080/14719030802002766

Hofstede, G. et al. (2010). Cultures and Organizations: Software of the Mind, Third Edition (3rd edition). McGraw-Hill. 
Holland, J. H. (2006). Studying Complex Adaptive Systems. Journal of Systems Science and Complexity, 19(1), pp. 1-8. <https://doi.org/10.1007/s11424006-0001-z>.

Hood, C. (1998). The Art of the State: Culture, Rhetoric, and Public Management. Oxford University Press.

Katz, R. S. (1997). Democracy and Elections by Richard S. Katz. Oxford University Press.

Klijn, E.-H. (2008). Complexity Theory and Public Administration: What's New? Public Management Review, 10(3), pp. 299-317. https://doi. org/10.1080/14719030802002675

Koliba, C. et al. (2016). Complexity theory, Networks and Systems Analysis. In C. Ansell and J. Torfing, eds., Handbook on Theories of Governance. Edward Elgar Publishing, pp. 364-379.

Merton, R. K. (1968). Social Theory and Social Structure. Free Press.

Miles, R.E. et al. (1978). Organizational Strategy, Structure, and Process. The Academy of Management Review, 3(3), pp. 546-562.

Miles, R. and Snow, C. (2003). Organizational Strategy, Structure, and Process ( $1^{\text {st }}$ edition). Stanford Business Books.

OECD. (1999). European Principles for Public Administration, SIGMA Papers, No. 27. At <http://www.oecd-ilibrary.org/docserver/download/5kml60zwdr7h.pd f?expires $=1459602912$ \&id=id\&accname $=$ guest\&checksum $=A D 84216916682$ 11416DB861810C0B737>, accessed 1 April 2019.

Ongaro, E. (2010). Public Management Reform and Modernization: Trajectories of Administrative Change in Italy, France, Greece, Portugal and Spain. Edward Elgar Pub.

Parsons, T. (1985). Talcott Parsons on Institutions and Social Evolution: Selected Writings. University of Chicago Press.

Pečarič, M. (2018a). Legal Principles as Extrapolated Reality. Archiv Für RechtsUnd Sozialphilosphie, 104(3), pp. 397-420.

Pečarič, M. (2018b). Means against the Rule of Nobody. DANUBE: Law and Economics Review, 3, pp. 135-152.

Pollitt, C. and Bouckaert, G. (2011). Public Management Reform: A Comparative Analysis - New Public Management, Governance, and the Neo-Weberian State (3rd edition). Oxford University Press.

Quah, J. S. T. (2010). Public Administration Singapore-Style. Emerald Group Publishing.

Rhodes, M. L. (2008). Complexity and Emergence in Public Management. Public Management Review, 10(3), pp. 361-379. https://doi. org/10.1080/14719030802002717

Rhodes, M. L. and MacKechnie, G. (2003). Understanding Public Service Systems: Is There a Role for Complex Adaptive Systems Theory? Emergence, 5(4), pp. 57-85. <https://doi.org/10.1207/s15327000em0504_6>

Rhodes, M.L. et al. (2010). Public Management and Complexity Theory: Richer Decision-Making in Public Services. Routledge.

Rhodes, M. L. and Murray, J. (2007). Collaborative Decision Making in Urban Regeneration: A Complex Adaptive Systems Perspective. International Public Management Journal, 10(1), pp. 79-101. https://doi. org/10.1080/10967490601185740 